\title{
Training of specialists for transport construction in the context of digitalization
}

\author{
$A$ Zhygadlo, $K$ Poleshchenko, and $Y u$ Kodentseva* \\ Siberian State Automobile and Highway University (SibADI), 5, Mira Avenue, Omsk, 644080, Russia
}

\begin{abstract}
The main goal of the study is to determine the direction of transformation of "SibADI" FSBEI $\mathrm{HE}$ as a center of attraction for all concentrated knowledge, skills and abilities in the development of the road industry, within the framework of the development conditions established by the scientific and technological revolution. This takes into account synchronization of all efforts on the part of scientific communities and industrial partners. Today, the Siberian State Automobile and Highway University faces the task of transforming from an industry-specific university with an accumulated scientific base. It includes transport construction, into an entrepreneurial University with commercialization of scientific, technical and educational and results in the following areas: "Creation and testing of intelligent composite materials"; "Creation of automated complexes for modeling multicomponent new road materials, including those of technogenic soils"; "Informational modeling of road objects with data transmission system"; "New methods of road diagnostics and defect recognition"; "Digital control, monitoring, forecasting systems"; "Intelligent logistics and design of network road configurations, as well as the development and transfer of entrepreneurial competencies into educational content". The specificity of training of engineers requires reaching a qualitatively new level, which makes it possible to enter the number of international recognized specialized universities, to solve ambitious tasks.
\end{abstract}

\section{Introduction}

A distinctive feature of the world economy is rapid development of science and technology. Emergence of end-to-end technologies indicates onset of a new stage of development in the economy. The challenges we face today determine the directions of transformation of scientific, educational institutions and technology companies to synchronize their efforts in achieving the goals set by the fourth scientific and technological revolution.

In addition, new entrepreneurial models become an element of such associations, which allow creating the effect of trust between the participants in the system, which leads to the emergence of cross-industry cooperation. Therefore, creation of a new mechanism for interaction and further development between science and industry through new models in the form of our proposed Competence Transfer Center on the basis of "SibADI" FSBEI HE will allow solving a role of a guide to new markets emerging at the intersection of industries.

Currently, the trend is to create a single research space in scientific communities based on the solution of the internal market, in which researchers, scientific knowledge and technologies will move freely, and with the help of which the technological base will be strengthened, competitiveness will increase and the ability to meet challenges collectively.

The tasks that "collaboration" solves are to increase the efficiency of research systems of the scientific community, find the optimal balance between cooperation and rivalry in interaction, remove barriers in the labor market for researchers, create conditions for the free exchange of knowledge and technologies, as well as the development of international cooperation. The development of such forms of interaction is also considered in the papers $[1,2,3]$.

\section{Materials and methods}

Transfer of competencies, taking into account emergence of a stack of end-to-end technologies, brings us to network forms of cooperation that form ecosystems around large scientific schools, allowing to use the potential of external scientific and industrial schools, research institutes, as well as science-based small and medium-sized businesses in order to solve the problems of the ecosystem formed around the scientific community. The creation of such an ecosystem in the form of the competence transfer center on the basis of "SibADI" FSBEI HE is considered in this article for preparation of highly qualified specialists who develop transport infrastructure in the context of digitalization. At the same time, the whole range of advanced 
technologies and approaches ensure high competitiveness of transport infrastructure facilities and structures that meet triad of requirements of the modern global market associated with reducing decision-making time, for the implementation and execution of projects, as well as for bringing products, facilities and structures to the market.

Therefore, "SibADI" FSBEI HE will have to transform from an industry-specific university with the accumulated scientific base for transport construction into an entrepreneurial University with commercialization of scientific, technical and educational results in the following areas: "Creation and testing of intelligent composite materials"; "Creation of automated complexes for modeling multicomponent new road materials, including those of technogenic soils"; "Informational modeling of road objects with data transmission system"; "New methods of road diagnostics and defect recognition"; "Digital control, monitoring, forecasting systems"; "Intelligent logistics and design of network road configurations, as well as the development and transfer of entrepreneurial competencies into educational content".

\section{Results and discussion}

In the point of view of public policy, technology transfer is of particular strategic importance, affecting the socioeconomic development of business entities. Taking into account the search for a regional agenda for the digital transformation of regions, this task as the transfer of competencies, mainly based on new technologies, also becomes an important task for the subjects of the Federation.

Historically, in 1930 SibADI was founded not by chance in the Omsk region, because the predominant physical and geographical location of the Omsk region allows developing and transferring technologies for the road construction industry in Siberia and the Far East with coverage of the Far North and transmission to the CIS countries. Development of social and economic condition of the region in terms of providing infrastructure, pace of development of buildings and structures in the region, ensuring availability and quality of transport and logistics services in the field of cargo transportation at the level of needs of the development of the regional economy is closely related to the participation of SibADI in these issues. Common tasks today are to solve the problems of reducing the outflow of the population and especially talented youth, creating comfortable studying conditions for them and further employment in the region.

To solve these goals, it was proposed to create on the basis of "SibADI" FSBEI HE the competence transfer center, the purpose of which is to create effective interface for interaction between scientific communities and interested industrial partners in developing the scientific potential of the industry and improving the training of highly qualified personnel for transport infrastructure.

The tasks of the center are development of strategic partnership in the system "University-industrial partner"; development of competencies of employees of enterprises, business structures and university employees in the field of technological management, technological entrepreneurship and technology brokerage; assistance in the formation of a personnel reserve of road enterprises, as well as assistance in the employment of graduates in the road infrastructure.

The idea of the Center is that during the formation of the competencies the future graduates, who are at the same time participants in scientific and educational entrepreneurial projects, in addition to mastering engineering skills and abilities, shall receive additional competencies of technology brokers, technology managers and technology entrepreneurs in order to provide intellectual and personnel support at all stages of development innovative technologies.

The focus of this Center is related to the current agenda of innovation and technological development of road enterprises according to the following existing problematic aspects:

- the lag between the pace of development of competencies among university graduates and engineering personnel and the pace of development of innovative technologies;

- lack of mobile infrastructure for educational training in the field of technology entrepreneurship;

- lack of universal models and effective mechanisms for forming project teams (communities of practice) in breakthrough areas of technological regional development.

The need for such transformation is due to the global trend of modern development - the formation of the modern innovative knowledge economy (the hypercompetitive, global, knowledge-driven economy of the $21^{\text {st }}$ century) in the context of the rapid development of technology, total computerization and automation, globalization and hypercompetition, constantly accelerating changes. The task of creating and developing the innovative knowledge economy, high technologies and science-intensive industries is becoming generally recognized.

The task is to create an "economy that generates and applies knowledge-based innovation", not generate "innovations" for their painful introduction into the economy. In this situation, universities face the choice: either to disappear as an educational institution, or to become active players in the "innovation field", both within the global or regional level. A necessary condition for embedding universities in global or regional innovation systems is acquisition of additional competence - entrepreneurial one, which inevitably leads to restructuring (transformation) of any university 
into the entrepreneurial university.

In the global innovation policy, the "triple helix" model (Henry Etzkowitz, Loet Leydesdorf) is widely spread, according to which universities are reorienting to the entrepreneurial model, in which the commercialization of scientific results and technical and technological developments plays a significant role.

The main feature of the entrepreneurial university is its focus on innovation. In addition to the traditional types of university activities: educational process and scientific research, project activities, as well as the entrepreneurial function in the form of technological entrepreneurship, are applied. Small and medium-sized innovative businesses build their development namely on the instruments of technological entrepreneurship - drivers of economic growth.

The difference of technological entrepreneurship is concluded in the fact that the creation of new products is directly related to the use of the latest scientific and technical knowledge, as well as technologies. The specificity of technology entrepreneurship is as follows:

- concentration on the discovery of new opportunities and the training of unique entrepreneurs in various areas of professional activity who can realize them;

- focus on project activities and project investment;

- ability of specialists to identify, select and develop new features of products and technologies (scientific and technological groundwork) in order to create and increase the value of an innovative product or technology.

The role and importance of technological entrepreneurship in the process of creating added value is steadily increasing. Consequently, there is the growing need for personnel capable of carrying out the relevant activities.

In addition, the problems of personnel training in the field of technology management and technology brokerage are becoming more acute.

The main benefits of the Center and such cooperation are the following:

1). Strengthening the role of industrial partners and universities in the development of regional and national economies.

2). Saving available funds in training of specialists;

3). Access to high-tech equipment;

4). Possibility of conducting internships for teachers at enterprises and improving the qualifications of employees of enterprises in universities;

5). Increasing the competitiveness of universities and industry enterprises.

Forms and models of strategic partnership are determined based on the goals, directions and resources available to the parties. Among them, two main areas of interaction can be noted.

First, the enterprise and the university are two parties of the educational process. The university is a manufacturer, and the enterprise is a consumer of specialists. Therefore, the degree to which the quality of training of specialists meets the wishes of the employer depends on the effectiveness of the feedback between them, and, consequently, the demand for a university graduate in production.

Secondly, the enterprise and the university, in accordance with global and domestic trends, become partners in the field of technology commercialization. At the same time, universities are increasingly trying to engage in technology transfer. Classification of existing forms and models of partnership between universities and enterprises is given below.

Existing models and interactions between Universities and industrial partners:

I. Educational programs.

- "Basic Department" and training of specialists under the order of the corporation;

• "Technology penetration";

II. Orders from industrial partners.

• "Business contracts";

• "Runaway Research Institute";

"R\&D orders from the state bodies" (218 Resolution, technological platforms, programs for innovative development of state corporations); IIP).

III. Development of new businesses (licenses, patents,

New forms of interaction between universities and industrial partners:

- independent platforms for cross-industry communication and industry foresight (independent associations of open innovation, clusters);

- creation of joint laboratories/research institutes and a "belt" of companies around the university;

- interaction of universities and companies;

- independent technology transfer centers.

Thus, the creation of the Competence Transfer Center will allow combining new forms of interaction between the University and industrial partners into one structure at the University and increase the efficiency of its work due to the transparency of management and synchronization of its activities under the direct requests of the industry.

The specificity of the Center's activities is determined by its main target function - the function of a "system moderator" that contributes to the formation and transfer of new competencies, mainly to support the joint R\&D activities of the university and industrial partners required at TRL3-TRL6 stages, as well as the competencies required for the commercialization of scientific and technical developments.

Therefore, the first "track" of the Center's activities should be focused on advanced formation of competencies necessary for the development of scientific and educational entrepreneurial projects by the type of REC projects, only being implemented both by individual faculties and by inter-faculty teams. 
The second "track" should be focused on the formation of intermediaries-entrepreneurs with design, innovation and intellectual competencies - technology brokers.

The tech broker is a scientist entrepreneur who is located at the interface between the academic world (developer, scientist) and the market (project packers, marketers). The main feature of the tech broker is that he is "deeply involved in the technology", in contrast to the packer-marketer and technology entrepreneur, who, rather, will only have superficial understanding of technological issues.

The functions of the tech broker turn out to be similar to the functions of the packer-marketer due to the fact that competencies are added with technical and technological knowledge that is combined with knowledge of product sales in the research area.

The competencies of the tech broker include the following:

- Organization of marketing and analytical work for the "packaging" of scientific technological groundwork.

- Working with roadmaps: ability to read company roadmaps and ability to draw up own research roadmaps.

- Competence in the field of "product management", development of project and commercial proposals.

- Creation of the system of innovative communications with scientists and industry representatives.

- Ability to accumulate competencies and use them for the further commercialization of $\mathrm{R} \& \mathrm{D}$ results.

The first step towards organizing educational forms of training of the tech brokers that are strategically important for both enterprises and universities could be a training program, including intensive trainings and tests, which would identify personnel who are inclined and able to work at the interface between university and industry.

The objectives of the Competence Transfer Center are the following:

1. To contribute to the achievement of partners' goals by developing their professional competencies in those areas of the economy, additional knowledge and skills in which they need to solve specific production and business problems.

2. To assist in the development of a system for improving professional competencies, attracting leading practicing domestic specialists to cooperation.

The tasks of the Center are the following:

1. To form a single communication platform based on the Transfer Center competences based on the exchange of experience and best practices.

2. To provide industrial partners with access to the best techniques and practices in the commercialization of their scientific and technical developments.

3. To provide methodological support to industrial partners at the level of preparation of analytical and information materials and their scientific and technological groundwork to prepare them for commercialization.

4. To develop the competencies of partners in the convenient mode for them, providing them with the opportunity to receive up-to-date information in the format convenient for them - through webinars.

In the future, the functions of the Center, in addition to the function of forming the competencies of participants in scientific and educational entrepreneurial projects, corresponding to the competencies of tech brokers, technology entrepreneurs and technology managers, can be expanded in accordance with both the needs of partner enterprises and the need to solve the strategic tasks of transforming SibADI into the entrepreneurial university.

\section{Conclusion}

This Competence Transfer Center complies with the current agenda, which determines the need for partnership between the university and industrial partners to reach a qualitatively new level, dictated by the need to intensify regional economic and technological development.

Today, neither industrial partners nor the university can exist without each other. The period of mutual disappointment has passed. New general and large-scale tasks have emerged that require mutually beneficial partnerships. New tasks require systematic, well-defined work in the most significant problem-oriented areas.

Analysis of foreign and domestic experience has shown that the minimum necessary (starting) conditions for the creation of entrepreneurial universities are:

- availability of partnerships with enterprises;

- availability of mechanisms for systematic support and stimulation of project-oriented and entrepreneurial activities contained in the innovation ecosystem of the university and allowing developers to overcome administrative barriers to the commercialization of innovations;

- availability of innovative and competent leaders at the university;

- availability of innovative and competent teams;

- availability of innovative scientific and educational projects (entrepreneurial projects).

In general, the expected results of the creation of the Competence Transfer Center will be determined by its positioning in the innovation ecosystem of the university, namely:

- as an element of the innovation ecosystem of the University, providing transfer of competencies based on the functioning of partner networks;

- as a coordinator of the activities of project teams (communities of practice) consisted of scientists, engineers, specialists and managers; 
- as an analytical center that provides joint activities of the University and industrial partners to create a portfolio of scientific and technological groundwork for the commercialization of scientific and technological developments.

In the short and medium term, the activities of the Competence Transfer Center can be focused on the implementation of the SibADI transformation program to the entrepreneurial university. In addition, the activities of the Center can be strategically effective in coordinating joint work with industrial partners.

\section{References}

1. D. Yu. Znamenskiy Upravlenie 7 (3) 12-20 (2019) doi: 10.26425/2309-3633-2019-3-12-20

2. A. O. Grudzinskiy, L. N. Zakhrova, Z. M. Saralieva The management staff of the University, 24-32 (2014)

3. K. Belyakov, A. Gavrilov, A. Ishenko, T. Poselova Technology transfer in the digital economy (Moscow: NATT, 2020)

4. M. V. Akulcheva, O. V. Sedova Economic and socio-humanitarian studies 2 (2) (2014)

5. I. V. Rozhdestvensky, O. I. Rozhdestvensky, A. Yu. Tarshin Innovations 11 (205) (2015)

6. A.N. Link, D.S. Siegel, M. Wright The Chicago Handbook of University Technology Transfer and Academic Entrepreneurship (University of Chicago Press, 2015) 